Abstracta Iranica Abstracta Iranica

Revue bibliographique pour le domaine irano-aryen

Volume 23 | 2002

Comptes rendus des publications de $\mathbf{2 0 0 0}$

\title{
Comparative Literature and Classical Persian Poetics. Seven Essays. Costa Mesa (California), Mazda Publishers, 2000, XVI-158 p.
}

\section{Charles-Henri de Fouchécour}

\section{(2) OpenEdition Journals \\ Édition électronique \\ URL : http://journals.openedition.org/abstractairanica/35791 \\ DOI : 10.4000/abstractairanica.35791 \\ ISSN : 1961-960X \\ Éditeur : \\ CNRS (UMR 7528 Mondes iraniens et indiens), Éditions de l'IFRI}

\section{Édition imprimée}

Date de publication : 15 mai 2002

ISSN : 0240-8910

\section{Référence électronique}

Charles-Henri de Fouchécour, "Comparative Literature and Classical Persian Poetics. Seven Essays. Costa Mesa (California), Mazda Publishers, 2000, XVI-158 p. », Abstracta Iranica [En ligne], Volume 23 2002, document 262, mis en ligne le 08 février 2010, consulté le 25 septembre 2020. URL : http:// journals.openedition.org/abstractairanica/35791 ; DOI : https://doi.org/10.4000/abstractairanica. 35791

Ce document a été généré automatiquement le 25 septembre 2020.

Tous droits réservés 


\title{
Comparative Literature and Classical Persian Poetics. Seven Essays. Costa Mesa (California), Mazda Publishers, 2000, XVI-158 p.
}

\author{
Charles-Henri de Fouchécour
}

Ces essais sont, pour une part, une défense vigoureuse par l'auteur de ses propres positions, pour une autre part un développement de ce qu'elle a tenu dans son ouvrage principal, Poet and hero in the Persian Book of Kings (Ithaca, Cornell Univ. Press, 1994, 8-197 p., Coll. Myth and Poetics) et dans plusieurs articles. Le premier essai est un rapide résumé du point de vue théorique à partir duquel elle a entrepris son travail sur le Livre des Rois de Ferdowsī, à savoir, à propos de la littérature orale, que le processus poétique oral offre deux aspects, de composition et de performance. Elle se réfère sur ce point aux travaux de Milman Parry autour du style formulaire de Homère, de A.B. Lord, sur The Singer of Tales (Cambridge, 1960) et, bien sûr, de Paul Zumthor, Introduction à la poésie orale (Seuil, 1983, 315 p., Coll. Poétique). Le second essai est la reprise et la défense de son article de 1998, sur le caractère formulaire des grands passages du Livre des Rois (voir Abs. Ir., 20-21, (2000), $\mathrm{n}^{\circ}$ 621). «Les lectures variées de différents manuscrits du Shâhnâme de Ferdowsi, écrit-elle, résultent d'un système de variation formulaire typique de la poésie orale»(p.10). Il s'agit d'une recomposition en performance. Est reprise ici la notion de mouvance d'un texte dans le temps, mise en valeur par P. Zumthor. Si bien que l'édition d'un texte comme celui du Šāhnāme doit rendre compte des variantes authentifiées, puisqu'il n'existe pas de bonnes ou de mauvaises variantes par rapport à un texte supposé originel. Ce doit être une édition en 'format multitext', rendant compte de la vie du texte aux données formulaires. « On ne peut recréer le texte fixe et archétypal du Shâhnâme ». Le troisième essai est consacré au problème des sources de Ferdowsī et de la façon dont lui et l'auteur de la Préface dite d'Abû Mansûr les ont présentées. O. M. Davidson veut montrer que le Livre des Rois n'est pas la mise en vers d'un texte en prose, mais une recréation à travers des traditions orales vivantes d'un ensemble à la fois écrit et oral. Le 'Ur-Text' est un 
mythe, et finalement un thème littéraire fréquent. Le quatrième essai est un chapitre polémique. Le cinquième est une défense de l'auteur contre l'accusation qui lui a été faite, à propos d'un article sur Rostam faiseur de rois (tăj-baHšs), de confondre sa fonction avec celle de Apam-Napât (Yasht 19), qui sauva la khwârnâh, 'force d'abondance' des anciens héros, de l'entreprise d'Afrāsiyāb. Il n'eut pas de fonction rituelle, ce qu'avait dans l'Avesta Apam-Napât. Le sixième essai est une analyse avec traduction du célèbre duel verbal de Rostam et d'Esfandiyār (Shâhnâme, éd. Mohl, vol. IV, 2972-3264). Le septième essai est l'analyse de la complainte de Tahmina après le meurtre par Rostam de leur fils Sohrāb, en exemple de l'institution sociale de la lamentation des femmes telle que Ferdowsī a su l'exploiter. L'ouvrage de O. M. Davidson permet de suivre dans son évolution une recherche fructueuse et prometteuse.

INDEX

Thèmes : 11.1.1. Littérature persane classique

\section{AUTEURS}

\section{CHARLES-HENRI DE FOUCHÉCOUR}

Sorbonne Nouvelle - Paris III 